\title{
Relationships between thought-action fusion, thought suppression and obsessive-compulsive symptoms: a structural equation modeling approach
}

Citation for published version (APA):

Rassin, E. G. C., Muris, P. E. H. M., Schmidt, H. G., \& Merckelbach, H. L. G. J. (2000). Relationships between thought-action fusion, thought suppression and obsessive-compulsive symptoms: a structural equation modeling approach. Behaviour Research and Therapy, 38, 889-897.

https://doi.org/10.1016/S0005-7967(99)00104-7

Document status and date:

Published: 01/01/2000

DOI:

10.1016/S0005-7967(99)00104-7

Document Version:

Publisher's PDF, also known as Version of record

Please check the document version of this publication:

- A submitted manuscript is the version of the article upon submission and before peer-review. There can be important differences between the submitted version and the official published version of record.

People interested in the research are advised to contact the author for the final version of the publication, or visit the DOI to the publisher's website.

- The final author version and the galley proof are versions of the publication after peer review.

- The final published version features the final layout of the paper including the volume, issue and page numbers.

Link to publication

\footnotetext{
General rights rights.

- You may freely distribute the URL identifying the publication in the public portal. please follow below link for the End User Agreement:

www.umlib.nl/taverne-license

Take down policy

If you believe that this document breaches copyright please contact us at:

repository@maastrichtuniversity.nl

providing details and we will investigate your claim.
}

Copyright and moral rights for the publications made accessible in the public portal are retained by the authors and/or other copyright owners and it is a condition of accessing publications that users recognise and abide by the legal requirements associated with these

- Users may download and print one copy of any publication from the public portal for the purpose of private study or research.

- You may not further distribute the material or use it for any profit-making activity or commercial gain

If the publication is distributed under the terms of Article $25 \mathrm{fa}$ of the Dutch Copyright Act, indicated by the "Taverne" license above, 


\title{
Relationships between thought-action fusion, thought suppression and obsessive-compulsive symptoms: a structural equation modeling approach
}

\author{
Eric Rassin*, Peter Muris, Henk Schmidt, Harald Merckelbach \\ Department of Psychology, Maastricht University, P.O. Box 616, 6200 MD Maastricht, Netherlands
}

Received 20 May 1999

\begin{abstract}
Research has shown that there are strong similarities in content between the obsessions and compulsions that characterize obsessive-compulsive disorder and nonclinical obsessions and compulsions. However, clinical and nonclinical obsessions and compulsions do differ with respect to characteristics like frequency, intensity, discomfort and elicited resistance. Two separate concepts have been invoked to explain how normal obsessions and compulsions may develop into clinical phenomena. First, it is suggested that thought-action fusion (TAF) contributes to obsessive-compulsive symptoms. Second, thought suppression may intensify obsessive-compulsive symptoms due to its paradoxical effect on intrusive thoughts. Although both phenomena have been found to contribute to obsessivecompulsive symptoms, possible interactions between these two have never been investigated. The current study explored how TAF and thought suppression interact in the development of obsessive-compulsive symptoms. Undergraduate psychology students $(N=173)$ completed questionnaires pertaining to TAF, thought suppression and obsessive-compulsive symptoms. Covariances between the scores on these questionnaires were analyzed by means of structural equation modeling. Results suggest that TAF triggers thought suppression, while thought suppression, in turn, promotes obsessive-compulsive symptoms. (C) 2000 Elsevier Science Ltd. All rights reserved.
\end{abstract}

Keywords: Obsessive-compulsive symptoms; Structural equation modeling; Thought-action fusion; Thought suppression

\footnotetext{
* Corresponding author.

E-mail address: e.rassin@psychology.unimaas.nl (E. Rassin).
}

0005-7967/00/\$ - see front matter (C) 2000 Elsevier Science Ltd. All rights reserved.

PII: S0005-7967(99)00104-7 


\section{Introduction}

Obsessions and compulsions are the core features of obsessive-compulsive disorder (OCD). According to the Diagnostic and Statistical Manual of Mental Disorders (DSMIV; APA, 1994, p. 418) "obsessions are persistent ideas, thoughts, impulses, or images that are experienced as intrusive and inappropriate and that cause marked anxiety or distress". Most obsessions involve thoughts about contamination, repeated doubts, a need to have things in a particular order, aggressive impulses, or sexual imagery (Rachman \& Hodgson, 1980). DSM-IV defines compulsions as "repetitive behaviors (e.g. hand washing, ordering, checking) or mental acts (e.g. praying, counting, repeating words silently) the goal of which is to prevent or reduce anxiety or distress, not to provide pleasure or gratification. In most cases, the person feels driven to perform the compulsion to reduce the distress that accompanies an obsession or to prevent some dreaded event or situation" (APA, 1994, p. 418). The most common compulsions involve cleaning and checking (Rachman \& Hodgson, 1980).

There is evidence to suggest that a majority of people experiences unpleasant intrusions similar to the obsessions seen in OCD. For example, Rachman and De Silva (1978) (see also Salkovskis \& Harrison, 1984) examined obsessive thinking in nonclinical subjects and OCD patients. These authors noted that about $80 \%$ of the nonclinical subjects experienced obsessions. Furthermore, they found remarkable similarities between 'abnormal' and 'normal' obsessions as far as the content of these obsessions is concerned. However, abnormal obsessions were found to be more frequent, intense, of longer duration and to produce more discomfort than normal obsessions. Muris, Merckelbach and Clavan (1997) compared compulsive behaviors of OCD patients with rituals of normal subjects. In accordance with the studies on abnormal and normal obsessions, these authors found a close correspondence between the content of abnormal and normal compulsions. Again, however, abnormal compulsions were more frequent and intense, elicited more discomfort and were more often associated with distressing thoughts and negative mood than normal compulsions. Taken together, these studies seem to demonstrate that normal intrusions and rituals and their clinical counterparts constitute one dimension.

Researchers have speculated about the antecedents that may be involved in the transformation of normal intrusions and rituals. Two main research lines have addressed this issue in a systematic and well-articulated manner. The first can best be referred to as the cognitive theory of obsession (Salkovskis, 1985; Rachman, 1993, 1997, 1998). The core assumption of this approach is that the interpretation that a person gives to an intrusive thought determines the obsessive qualities of that intrusion. By this view, a person who feels extremely responsible for his or her thoughts, will experience more discomfort when an 'immoral' thought (e.g. about sex or violence) intrudes consciousness than a person without such an inflated sense of responsibility. Persons suffering from an exaggerated sense of responsibility may think that immoral intrusions indicate them to be bad. Such an appraisal may add obsessive qualities (e.g. increased discomfort, tension, anxiety and resistance) to intrusive thoughts. Rachman, Thordarson, Shafran and Woody (1995), presented a refined version of this cognitive account of OCD. That is, their work demonstrated that two types of cognitive biases are specifically associated with obsessive-compulsive symptoms. The first bias 
implies that having a thought of a particular, unpleasant situation (e.g. a car accident) increases the likelihood that such situation will actually occur. This bias is known as likelihood or probability bias. The second bias boils down to the notion that having immoral thoughts (even involuntary ones) about, for example, violence is as bad as immoral behavior (e.g. acting violently). The latter bias is referred to as morality bias. Together, probability and morality bias constitute the concept of 'thought-action fusion' (TAF; Shafran, Thordarson \& Rachman, 1996). TAF is thought to represent the tendency to overevaluate the significance and consequences of intrusive thoughts.

A second research line has emphasized the role of thought suppression in the exacerbation of intrusive thoughts. There is evidence to suggest that cognitive avoidance strategies such as thought suppression may be counterproductive. For example, Wegner, Schneider, Carter and White (1987) found that suppression attempts result in more rather than less intrusions. This paradoxical phenomenon is often referred to as the 'white bear effect'. Clearly, an increased frequency of unwanted intrusions is in itself an obsessive feature. In addition, a heightened frequency may lead to more discomfort and increased perceived intensity. Accordingly, Wegner (1989, p. 167) claims that the paradoxical effect of thought suppression can result in full blown obsessions: "An obsession can grow from nothing but the desire to suppress a thought".

Note, in passing, that both research lines have focused on factors that intensify intrusive thinking, thereby assuming that compulsive behaviors are a function of intrusive thinking. In this view, compulsions can best be understood as a response to obsessions. This would imply that an exacerbation of intrusions is followed by an increase in compulsive behavior. There are good reasons to believe that both TAF (see Rachman, Shafran, Mitchell, Trant \& Teachman, 1996) and thought suppression (see Rassin, Merckelbach \& Muris, in press), indeed, contribute to the exacerbation of obsessive-compulsive symptoms. However, little is known about the interactions between TAF and thought suppression. Of course, TAF may trigger suppression attempts. In Rachman's (1998, p. 393) words: "an inflated increase in the significance attached to an unwanted intrusive thought, such as an obsession, will lead to more vigorous and intense attempts to suppress such thoughts". Another possibility is that the interaction between TAF and suppression takes the form of a vicious circle, "Given that patients can misinterpret the frequency with which they experience the obsession as evidence for the importance of the obsession (...), paradoxical increases in frequency that arise from attempts at suppression, may actually strengthen the catastrophic misinterpretation themselves. A vicious cycle is established" (Rachman, 1998, p. 394). Still other interactions become possible when the two TAF components of probability and morality are considered separately ( $\mathrm{S}$. Rachman, pers. comm., September 29, 1998). One could argue, for instance, that TAF-probability may be directly related to obsessive-compulsive symptoms. Consider this example: a man who is plagued by a probability bias experiences an intrusion about his wife being involved in a car accident. Subsequent suppression attempts (even if successful) will not be sufficient to reassure him. Therefore, rather than cognitively avoiding the intrusion, he will engage in actions or cognitions that prevent the expected consequences (i.e., his wife actually crashing her car) from happening. For example, he might ask his wife not to travel by car, or he might engage in mental acts (e.g. praying). Thus, a probability bias may directly fuel obsessive-compulsive symptoms. On the other hand, a morality bias does not necessarily force the person who experiences an immoral intrusion to prevent anticipated consequences, since this type of bias 
does not involve such consequences. Following this line of reasoning, morality does not trigger neutralizing rituals, but it may give rise to suppression, as intrusions are experienced as extremely unpleasant. If this analysis is correct, one would predict that probability directly increases obsessive-compulsive symptoms, whereas morality is thought to trigger suppression attempts which, in turn, lead via the paradoxical effect of thought suppression, to obsessivecompulsive symptoms. To sum up, then, there are a number of intuitively plausible models about the dynamics between TAF, thought suppression and OCD. Yet, empirical evidence to evaluate the merits of these models is lacking.

The present study explored possible interactions between TAF and thought suppression in the exacerbation of obsessive-compulsive symptoms. Normal subjects completed questionnaires measuring TAF, thought suppression and obsessive-compulsive symptoms. Then, the relationships between these three constructs were examined by means of structural equation modeling. A number of plausible models were tested. In the first model, TAF and thought suppression independently contribute to obsessive-compulsive symptoms. In the second model, TAF leads to thought suppression, which, in turn, results in obsessive-compulsive symptoms. To investigate whether thought suppression actually is an antecedent of obsessive-compulsive symptoms, or rather, a consequence of such symptoms, a third model was tested in which TAF leads to obsessive-compulsive symptoms, whereas these symptoms trigger thought suppression. In the fourth and fifth model, TAF was broken down in its probability and morality components. Model 4 followed the same route as model 2, which means that both probability and morality result in thought suppression, while thought suppression leads to obsessive-

compulsive symptoms. Model 5 tested the hypothesis that probability is directly related to obsessive-compulsive symptoms, whereas morality indirectly influences these symptoms through thought suppression. Fig. 1 provides schematic representations of the 5 models. Note that Fig. 1 also provides empirically established path coefficients.

\section{Method}

\subsection{Subjects}

A sample of 173 undergraduate psychology students (131 females) participated in the study. They received a small financial compensation for their participation. Mean age was 19.1 years (S.D. $=1.7$; range: $17-28$ years).

\subsection{Materials}

Subjects completed the following self-report questionnaires. The thought-action fusion scale (TAF scale; Shafran et al., 1996) consists of 19 items which are scored on a 5-point answer format $(0=$ disagree strongly; $4=$ agree strongly). The TAF scale taps two components (cf. supra): probability (7 items, e.g. "If I think of a relative/friend being in a car accident, this increases the risk that he/she will have a car accident") and morality (12 items, e.g. "If I wish harm on someone, it is almost as bad as doing harm"). A total TAF score can be calculated by summing all items. Higher scores indicate a stronger TAF tendency and, by implication, an 


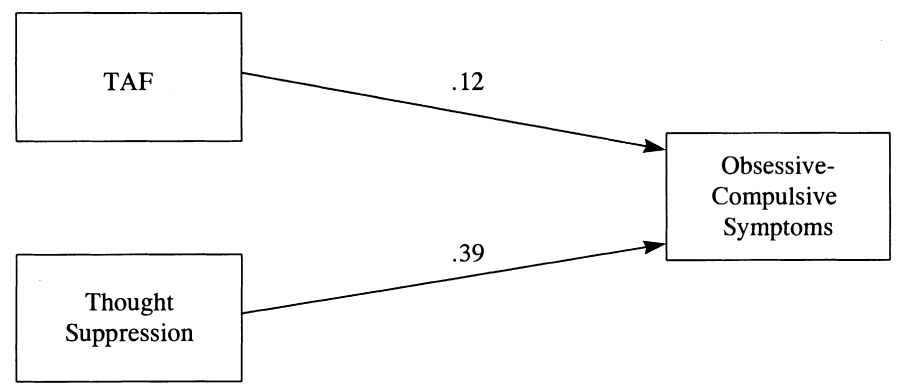

Model 2

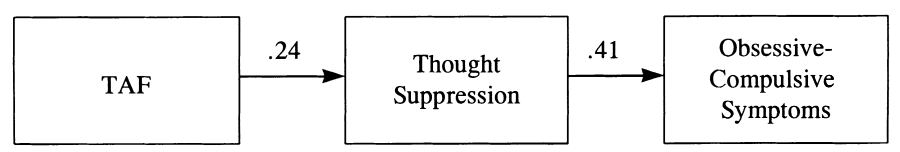

$\underline{\text { Model } 3}$

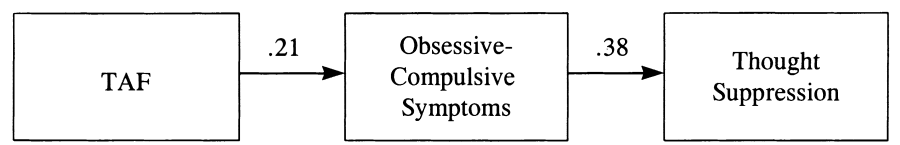

\section{$\underline{\text { Model } 4}$}

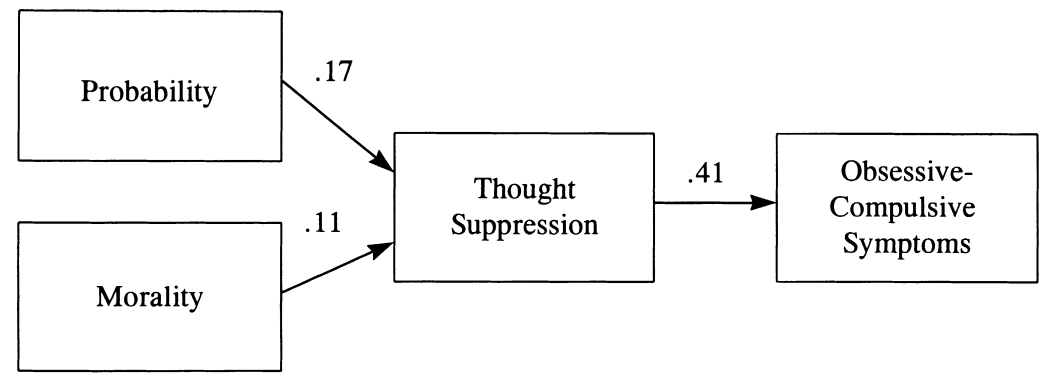

Model 5

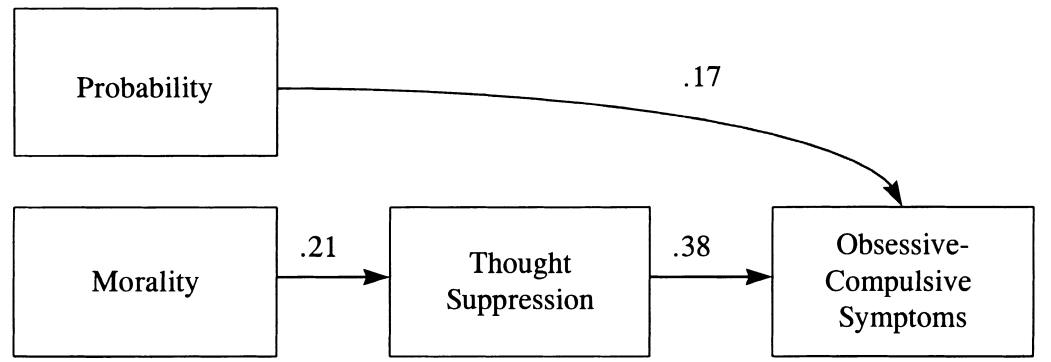

Fig. 1. Schematic representations of the 5 models. 
inflated sense of responsibility for one's own thoughts. The white bear suppression inventory (WBSI; Wegner \& Zanakos, 1994) consists of 15 items pertaining to the chronic tendency to suppress unwanted thoughts. WBSI items (e.g. "I always try to put problems out of mind") are scored on a 5 -point scale $(1=$ strongly disagree; $5=$ strongly agree $)$. Thus, total scores range from 15 to 75, with higher scores reflecting stronger tendencies to suppress unpleasant thoughts. The Maudsley obsessive-compulsive inventory (MOCI; Hodgson \& Rachman, 1977) consists of 30 true/false items describing various obsessive-compulsive symptoms such as checking (e.g. "My major problem is repeated checking"), cleaning (e.g. "I avoid using public telephones because of possible contamination"), doubting (e.g. "Even when I do something very carefully I often feel that it is not quite right") and slowness (e.g. "I am often late because I can't seem to get through everything on time"). Every endorsed item yields one point, so that total scores range from 0 to 30, with higher scores indicating the presence of more obsessivecompulsive symptoms.

\subsection{Analyses}

The structural equation modeling program EQS (Bentler, 1989) was used to analyze the data. EQS combines multiple regression and path analysis. It provides a powerful approach to test plausible models that may underlie a data set. EQS produces several goodness-of-fit indices indicating how well the tested model accounts for the observed correlational structure of the data. In the present study, the following indices were used: (1) the $\chi^{2}$ goodness of fit value, which is required to be nonsignificant for the tested model to provide a good fit for the data, (2) the average off diagonal absolute standardized residuals (AASR), which should not exceed 0.05 in order for the model to fit the data well, (3) Akaike's information criterion (AIC) which is a fit index that takes into account the parsimony of the tested model (i.e., the number of included paths); AIC is a relative measure: that is to say, the model with the smallest number provides the best fit and (4) the comparative fit index (CFI) which compares the fit of the model with the hypothetical model in which none of the variables are correlated. A CFI of 0.90 or higher indicates that the tested model fits the data well (see, for an extensive discussion of these indices, Schumacker \& Lomax, 1996).

\section{Results}

Mean score on the TAF scale was $21.1($ S.D. $=10.4)$. Means for the probability and morality subscales were 7.0 (S.D. $=4.8$ ) and 14.2 (S.D. $=7.8)$, respectively. The average WBSI score was 50.6 (S.D. $=9.7$ ) and the mean score on the MOCI was 6.7 (S.D. $=4.7)$. The internal consistency of the total TAF scale $(\alpha=0.87)$, TAF-probability $(\alpha=0.77)$, TAF-morality $(\alpha=0.86)$, WBSI $(\alpha=0.86)$ and MOCI $(\alpha=0.76)$ proved to be satisfactory. Table 1 presents Pearson product-moment correlations between the various questionnaires.

The fit indices for the 5 models are summarized in Table 2 . As can be seen, models 1 and 3 provide poor fits for the data. The $\chi^{2}$ values reach significance $(p<0.05)$ and the unexplained variances of these models (AASR) exceed 0.05 .

Models 2, 4 and 5 have satisfactory fits. The $\chi^{2}$ values for these models all remain 
Table 1

Pearson correlations between the various questionnaires. $N=173$; TAF $=$ thought - action fusion scale; WBSI $=$ white bear suppression inventory; MOCI = Maudsley obsessive-compulsive inventory. ${ }^{*} p<0.01$

\begin{tabular}{lllll}
\hline & TAF-total & TAF-probability & TAF-morality & WBSI \\
\hline TAF-probability & $0.70^{*}$ & - & & \\
TAF-morality & $0.90^{*}$ & $0.32^{*}$ & - & \\
WBSI & $0.24^{*}$ & $0.16^{*}$ & $0.21^{*}$ & - \\
MOCI & $0.21^{*}$ & $0.23^{*}$ & 0.13 & $0.41^{*}$ \\
\hline
\end{tabular}

nonsignificant $(p>0.05)$, there is little unexplained variance (AASR $<0.05)$ and the CFIs are good $(>0.90)$. Note also that model 5 (in which probability leads to obsessive-compulsive symptoms and morality leads to thought suppression) produces the best fit. The $\chi^{2}$ value is nonsignificant $(p=0.39)$, the residuals are small (AASR $=0.03)$ and the CFI is high $(1.00)$.

\section{Discussion}

The current results can be interpreted as follows. First, TAF and thought suppression seem to interact in the development of obsessive-compulsive symptoms, in that TAF leads to suppression attempts, while suppression, paradoxically, results in more obsessive-compulsive symptoms (model 2). This causal chain is more likely than a scenario in which TAF and suppression independently contribute to such symptoms (model 1). Furthermore, the results suggest that suppression is, indeed, an antecedent of obsessive-compulsive symptoms, rather than a mere reaction to such symptoms (as is the case in model 3). When TAF is broken down into its probability and morality components, a causal model assuming that these two biases trigger thought suppression, which, in turn, results in more obsessive-compulsive symptoms, still provides a good fit for the data (model 4). However, given the data, it seems more likely that the probability bias directly affects obsessive-compulsive symptoms (model 5).

Some limitations of the present study should be acknowledged. First, the study relied on a

Table 2

Fit-indices for the 5 models. AASR = average off-diagonal absolute standardized residuals; AIC $=$ Akaike's information criterion; $\mathrm{CFI}=$ comparative fit index

\begin{tabular}{llllll}
\hline & $\chi^{2}$ & $p$ & AASR & AIC & CFI \\
\hline Model 1 & 9.77 & 0.00 & 0.12 & 7.77 & 0.78 \\
Model 2 & 2.54 & $0.11^{\mathrm{a}}$ & $0.04^{\mathrm{a}}$ & 0.54 & $0.96^{\mathrm{a}}$ \\
Model 3 & 7.69 & 0.02 & 0.05 & 3.69 & 0.86 \\
Model 4 & 5.73 & $0.06^{\mathrm{a}}$ & $0.04^{\mathrm{a}}$ & 1.73 & $0.94^{\mathrm{a}}$ \\
Model 5 & 1.87 & $0.39^{\mathrm{a}}$ & $0.03^{\mathrm{a}}$ & $-2.13^{\mathrm{a}}$ & $1.00^{\mathrm{a}}$ \\
\hline
\end{tabular}

\footnotetext{
a Indicative for a good fit.
} 
sample of healthy subjects. Future studies should examine whether the current results can be replicated in a clinical sample. Second, the study relied on concurrent measurements. Nevertheless, the results fit nicely with current theoretical notions on the etiology of obsessivecompulsive symptoms and they may help to design experiments examining the interactions between TAF and suppression.

The current findings imply that TAF is a more fundamental cause of obsessive-compulsive symptoms than is thought suppression. Given that the models 2, 4 and 5 all fit better than model 1, thought suppression seems to have an intermediate role between TAF and obsessivecompulsive symptoms, rather than a primary causal one. This underscores the idea that therapeutic interventions for OCD should address patients' cognitive biases. To the extent that these biases are corrected, the urge to engage in thought suppression should also decrease. On the other hand, reducing the chronic avoidant coping style, would leave the TAF bias intact. This analysis suggests that the TAF bias deserves priority. Thus, the present results support Rachman's conclusion "that the most direct and satisfactory treatment of obsessions is to assist patients in the modification of the putatively causal catastrophic misinterpretations of the significance of their intrusive thoughts. Bluntly, if these misinterpretations are 'corrected', the obsession should cease" (1997, p. 799).

\section{References}

American Psychiatric Association (1994). Diagnostic and statistical manual of mental disorders (4). Washington: American Psychiatric Association.

Bentler, P. (1989). EQS Structural Relations Program manual. Los Angeles: BMDP Statistical Software.

Hodgson, R. J., \& Rachman, S. (1977). Obsessional-compulsive complaints. Behaviour Research and Therapy, 15, 389-395.

Muris, P., Merckelbach, H., \& Clavan, M. (1997). Abnormal and normal compulsions. Behaviour Research and Therapy, 35, 249-252.

Rachman, S., \& De Silva, P. (1978). Abnormal and normal obsessions. Behaviour Research and Therapy, 16, 233248.

Rachman, S., \& Hodgson, R. (1980). Obsessions and compulsions. Englewood Cliffs, NJ: Prentice Hall.

Rachman, S. (1993). Obsessions, responsibility and guilt. Behaviour Research and Therapy, 31, $149-154$.

Rachman, S. (1997). A cognitive theory of obsessions. Behaviour Research and Therapy, 35, 793-802.

Rachman, S. (1998). A cognitive theory of obsessions: elaborations. Behaviour Research and Therapy, 36, 385-401.

Rachman, S., Thordarson, D. S., Shafran, R., \& Woody, S. R. (1995). Perceived responsibility: structure and significance. Behaviour Research and Therapy, 33, 779-784.

Rachman, S., Shafran, R., Mitchell, D., Trant, J., \& Teachman, B. (1996). How to remain neutral: an experimental analysis of neutralization. Behaviour Research and Therapy, 34, 889-898.

Rassin, E., Merckelbach, H., Muris, P. (in press). Paradoxical and less paradoxical effects of thought suppression: a critical review. Clinical Psychology Review.

Salkovskis, P. M., \& Harrison, J. (1984). Abnormal and normal obsessions: a replication. Behaviour Research and Therapy, 22, 549-552.

Salkovskis, P. M. (1985). Obsessional-compulsive problems: a cognitive-behavioural analysis. Behaviour Research and Therapy, 23, 571-583.

Schumacker, R. E., \& Lomax, R. G. (1996). A beginner's guide to structural equation modeling. Mahwah, NJ: Lawrence Erlbaum associates, publishers.

Shafran, R., Thordarson, D. S., \& Rachman, S. (1996). Thought-action fusion in obsessive compulsive disorder. Journal of Anxiety Disorders, 10, 379-391. 
Wegner, D. M. (1989). White bears and other unwanted thoughts: suppression, obsession and the psychology of mental control. London: The Guilford press.

Wegner, D. M., \& Zanakos, S. (1994). Chronic thought suppression. Journal of Personality, 62, 615-640.

Wegner, D. M., Schneider, D. J., Carter, S. R., \& White, T. L. (1987). Paradoxical effects of thoughts suppression. Journal of Personality and Social Psychology, 53, 5-13. 